\title{
Fixating on metals: new insights into the role of metals in nodulation and symbiotic nitrogen fixation
}

\author{
Manuel González-Guerrero ${ }^{1}$, Anna Matthiadis ${ }^{2}$, Ángela Sáez ${ }^{1}$ and Terri A. Long ${ }^{2}$ * \\ ${ }^{1}$ Centro de Biotecnología y Genómica de Plantas, Universidad Politécnica de Madrid, Madrid, Spain \\ ${ }^{2}$ Department of Plant and Microbial Biology, North Carolina State University, Raleigh, NC, USA
}

\section{Edited by:}

Paloma Koprovski Menguer.

Universidade Federal do Rio Grande

do Sul, Brazil

\section{Reviewed by:}

Heiner Goldbach, University of Bonn Germany

Hong-Qing Ling, Institute of Genetics and Developmental Biology-Chinese

Academy of Sciences, China

\section{*Correspondence:}

Manuel González-Guerrero, Centro de Biotecnología y Genómica de Plantas, Universidad Politécnica de Madrid, Campus de Montegancedo, Carretera M-40, Km 38, 28223-Pozuelo de Alarcón Madrid, Spain

e-mail: manuel.gonzalez@upm.es;

Terri A. Long, Department of Plant and

Microbial Biology, North Carolina

State University, Raleigh, NC 27695,

USA

e-mail: terri_long@ncsu.edu
Symbiotic nitrogen fixation is one of the most promising and immediate alternatives to the overuse of polluting nitrogen fertilizers for improving plant nutrition. At the core of this process are a number of metalloproteins that catalyze and provide energy for the conversion of atmospheric nitrogen to ammonia, eliminate free radicals produced by this process, and create the microaerobic conditions required by these reactions. In legumes, metal cofactors are provided to endosymbiotic rhizobia within root nodule cortical cells. However, low metal bioavailability is prevalent in most soils types, resulting in widespread plant metal deficiency and decreased nitrogen fixation capabilities. As a result, renewed efforts have been undertaken to identify the mechanisms governing metal delivery from soil to the rhizobia, and to determine how metals are used in the nodule and how they are recycled once the nodule is no longer functional. This effort is being aided by improved legume molecular biology tools (genome projects, mutant collections, and transformation methods), in addition to state-of-the-art metal visualization systems.

\section{Keywords: symbiotic nitrogen fixation (SNF), metals, legume, rhizobia, nodule, iron, zinc, copper}

releases rhizobia into the cytosol of nodule primordial cells within the root cortex. The rhizobia and their surrounding peribacteroid membrane (PBM), together known as the symbiosome, continue to divide until cells are filled with thousands of symbiosomes (for review, see Udvardi and Poole, 2013). Eventually, the bacteria within the symbiosomes stop dividing and differentiate into nitrogen-fixing bacteroids.

Many legumes from tropical and subtropical regions (soybean, bean) and some from temperate regions (Lotus japonicus) develop determinate nodules, in which meristem activity halts, causing the formation of a spherical nodule. In contrast, most other temperate legumes, including those in the genera Medicago, Trifolium, and Pisum, develop indeterminate nodules. Indeterminate nodules maintain a nodule meristem at the growing tip (zone I), followed by a zone of infection where rhizobia are released from the infection thread (zone II), a nitrogen fixation zone (zone III), and finally, a senescence zone in which bacteroids are degraded and nitrogen fixation ceases (zone IV; Vasse et al., 1990). Nutrient exchange at the nodule is facilitated by vascular vessels that surround cortical infected and uninfected cells.

\section{METAL FUNCTIONS IN THE ESTABLISHMENT OF SNF}

Metals are key elements of all living organisms (Frausto da Silva and Williams, 1991) and are an integral part of $30-50 \%$ of the proteome of a typical cell (Waldron and Robinson, 2009). They are also involved in every biological process, including the legume-specific stages of SNF from rhizobia infection to nodule 
senescence. During the initial stages of infection, manganese and calcium facilitate rhizobial colonization of the root by mediating rhizobial lectin binding to the root hair tips (Kijne et al., 1988). Later stages of SNF signaling are mediated by calcium-spiking in the perinuclear region. As a result, calcium-calmodulin dependent kinases (CCaMKs) are activated (Singh and Parniske, 2012). CCaMKs induce the expression of genes mediating nodulation via the transcription factors NSP1/2 or NIN (Kalo et al., 2005; Andriankaja et al., 2007). Additionally, high levels of potassium have been detected in the apical region of indeterminate nodules, where it might play a role in cell growth (Rodríguez-Haas et al., 2013). Potassium also acts as the counter-ion compensating calcium in earlier signaling processes, via transport processes putatively mediated by channels such as CASTOR, POLLUX or DMI1 (Peiter et al., 2007; Charpentier et al., 2008, 2013). Also, cobalt, a component of cobalamin in ribonucleotide reductases, is essential for rhizobia endoreduplication, which occurs during differentiation into bacteroids (Taga and Walker, 2010).

Iron is the key cofactor of many metabolic reactions involved in SNF. In the early stages of nodulation, heminic iron is critical for catalase-mediated free radical detoxification (Jamet et al., 2003). Upon nodule maturation, iron is required for nitrogenase and leghemoglobin activity. The bacterial nitrogenase complex is necessary for the actual production of a usable nitrogen source (ammonia) from atmospheric nitrogen. NifH and NifDK, components of the nitrogenase complex, require iron-sulfur clusters and the iron-molybdenum cofactor, respectively. In contrast, leghemoglobin, the most abundant protein in the nodule cytosol, contains heminic iron. It effectively buffers oxygen content in the nodule, allowing for levels sufficient for bacteroid respiration without inactivating nitrogenase. Heminic iron is also critical for energy transduction by rhizobia cytochromes (Reedy and Gibney, 2004). Free iron, directly coordinated by amino acids, is involved in free radical detoxification as part of Fe-superoxide dismutases (Fe-SOD; Rubio et al., 2007).

Copper also plays a critical role in nitrogen fixation. Increased copper application results in elevated nitrogen fixation per nodule and increased nitrogen content in plant tissue (Hallsworth et al., 1960; van der Elst et al., 1961; Snowball et al., 1980; Seliga, 1990, 1993). This element is a cofactor of some of the high affinity cytochromes mediating energy transduction in the bacteroid (Preisig et al., 1996). It is also part of several superoxide dismutase systems detoxifying abundant free radicals produced as side products of SNF (Rubio et al., 2007). Additionally, zinc and manganese are integral elements of many superoxide dismutases (Rubio et al., 2007). Zinc is also involved in gene regulation as part of the zinc-finger motif of many transcription factors (Klug, 2010).

Some rhizobia are able to conserve energy by oxidizing $\mathrm{H}_{2}$ produced during nitrogen fixation via the uptake hydrogenase enzyme, Hup (Emerich etal., 1979). Hup contains nickel, and alterations in nickel supply have been shown to affect Hup activity and formation in soybean and pea (Klucas et al., 1983; Stults et al., 1984; Brito et al., 1994, 1997). Therefore, although not required for nitrogen fixation, nickel can enhance the effectiveness of SNF in those species containing hydrogenase-encoding species, and may prove more critical if breeding and engineering efforts focused around this enzyme are successful.

\section{TRANSITION METAL UPTAKE AND DISTRIBUTION IN SNF}

Transition metal transport processes in the nodule are summarized in Figure 1. Legumes are Strategy I plants (Andaluz et al., 2009), i.e., iron is incorporated after acidification of the soil, which increases $\mathrm{Fe}^{3+}$ solubility. Ferroreductase can then reduce $\mathrm{Fe}^{3+}$ to $\mathrm{Fe}^{2+}$, which is finally transported into the epidermal cell by ZIP or NRAMP family members (Curie et al., 2000; Morrissey and Guerinot, 2009; Figure 1A). Copper is likely incorporated in a similar manner. $\mathrm{Cu}^{2+}$ is reduced to $\mathrm{Cu}^{+}$and a member of the copper transporter (Ctr) family translocates the metal across the epidermal cell plasma membrane. $\mathrm{Zn}^{2+}$ and other divalent ions are possibly directly introduced by ZIP or NRAMP family members. Many dicots will also secrete organic acids, phenolics, flavins, and flavonoid compounds under iron deficiency (Rodríguez-Celma et al., 2013). Phenolic compounds have recently been shown to modify the rhizosphere microbial community, leading to increased synthesis of the metal chelators and siderophores in red clover (Jin et al., 2006), which may also facilitate root metal uptake.

Symbiotic nitrogen fixation exerts a heavy toll on plant metal reserves, eliciting up-regulation of metal uptake systems (Terry et al., 1991). Recently, Slatni etal. (2011) measured the overall contribution of nodule versus root in rhizospheric iron uptake, noticing increased ferroreductase activity in the nodule. This could be due to the nodule epidermis playing a major role in iron uptake. Alternatively, since the ferroreductase activity was measured in the microsomal fraction of nodule extracts, some of this increased activity could result from ferroreductases working within the nodule cortex. This alternative hypothesis would take into account that the $\mathrm{Fe}^{3+}$, transported as a citrate complex (Rellán-Álvarez et al., 2010), would have to be reduced to $\mathrm{Fe}^{2+}$ in the nodule cortex in order to be incorporated by the vasculature cells. In addition, $\mathrm{H}^{+}$ATPases and ZIP family members are expressed in the epidermal layer, in close proximity to the vasculature, and in the nitrogen fixation zone of the nodule (Slatni et al., 2012). These observations indicate that iron is present in the apoplast of the nodule cortex and, therefore, cortical cells use these proteins to uptake apoplastic iron.

Synchrotron-based X-ray fluorescence (S-XRF) studies indicate that some legumes with indeterminate nodules deliver iron, and likely other metals, to the nodule through the vasculature rather than using an epidermal pathway (Rodríguez-Haas et al., 2013). The metal distribution throughout different regions of the nodule indicates that there is a massive accumulation of iron around the vascular cells in zone II extending into the nodule cortical cells. Interestingly, this is where symbiosis is established and the symbiosomes differentiate. Iron accumulation in the apoplast would require plasma membrane metal transporters to introduce this element into the cytosolic compartment to synthesize ferroproteins. This transport system seems to be very efficient, since very little or no apoplastic iron is observed in the nitrogen fixation zone of the nodule. Researchers speculate that a ZIP or NRAMP transporter, both involved in divalent metal uptake (Nevo and Nelson, 2006; Lin et al., 2010), are the likely candidates (Figures 1A,B). 
A

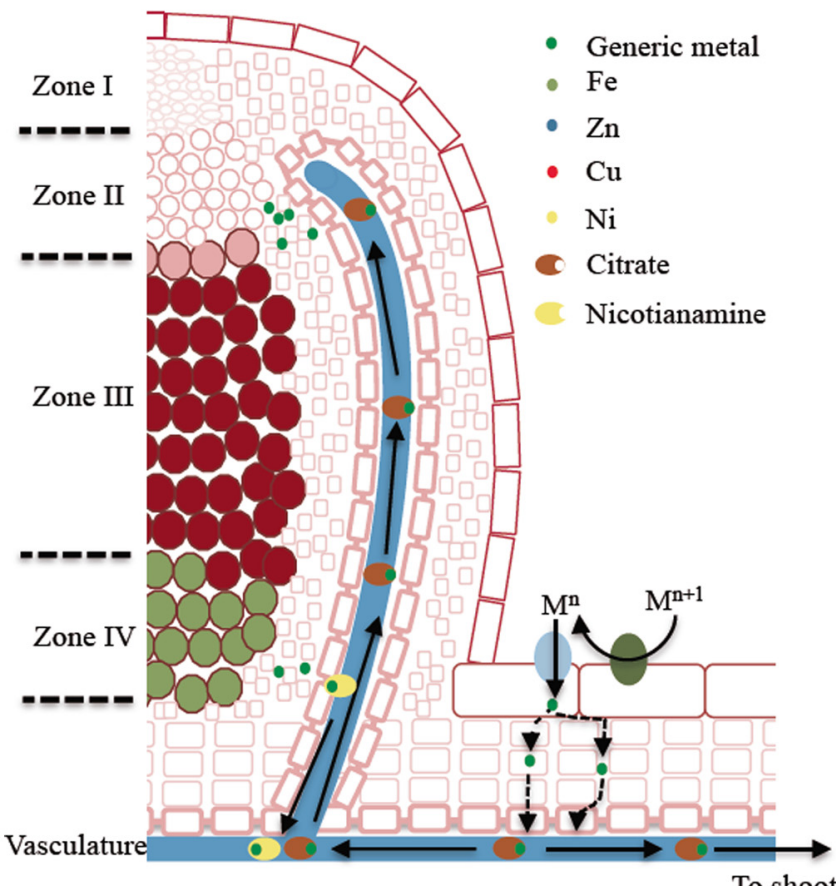

B

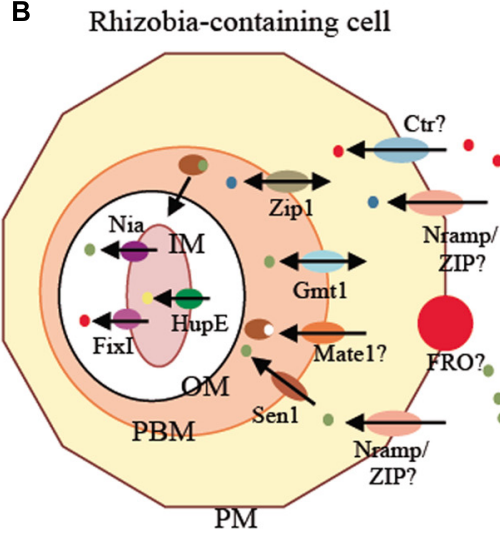

Nodule endodermis

C

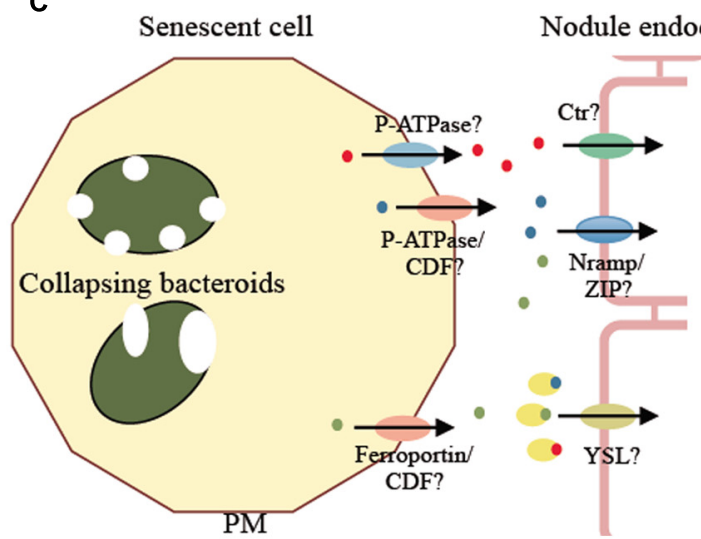

FIGURE 1 | Model of transition metal transport in indeterminate type nodules. (A) Overview of the metal delivery mechanism. Metals are typically incorporated following Strategy I, i.e., reduction by a plasma membrane ferroreductase and uptake by plasma membrane metal transporters. This process occurs over the entire epidermal surface of the root, including the nodule. Metals reach the vasculature where they bind metal chelators as citrate. The metal citrate complex is delivered to zone II of the nodule (infection/differentiation zone) and the metal is released into the apoplast and subsequently incorporated into the infected cell. In zone IV (senescence zone), metals are released to the apoplast, associated with nicotianamine, and translocated into the vasculature. (B) Proposed model of metal delivery from the vasculature to zone II. Proposed transporter families to carry out ion transport are indicated with a question mark. (C) Proposed model of metal recovery from the senescent zone of the nodule. Proposed transporter families are indicated with a question mark. PM indicates plasma membrane; PBM, peribacteroid membrane; OM, bacterial outer membrane; and IM, bacterial inner membrane.
ZIP family members have been immunodetected in the nodule (Slatni et al., 2012). However, the only ZIP family member characterized in this organ, GmZIP1, seems to be localized in the PBM (Moreau et al., 2002), where it is predicted to play a role in $\mathrm{Zn}^{2+}$ transport. In this membrane, an $\mathrm{Fe}^{2+}$-transporting NRAMP member, GmDMT1, is also present (Kaiser et al., 2003; Figure 1B). These transporters may be involved in metal transport to the symbiosome. However, biochemical analysis of members of these two families and yeast complementation studies indicate that neither transporter could play a role in metal transfer to the symbiosome (Nevo and Nelson, 2006; Lin et al., 2010), instead they appear to transport metals towards the cytosol. The localization observed could be the result of the endocytic process mediating rhizobia release into the host cell (Leborgne-Castel et al., 2010), which would also carry plasma membrane associated transporters.

A more likely candidate for iron transport into the symbiosome is SEN1 (Figure 1B). The sen1 mutant in L. japonicus has a number of alterations in nodulation that are associated with the lack of nitrogenase activity, most likely due to a deficiency in iron loading of the symbiosomes (Hakoyama et al., 2012). The proposed role of SEN1 in iron transport is due to its close sequence similarity to Saccharomyces cerevisiae CCC1 and Arabidopsis thaliana VIT1 proteins, both involved in divalent metal ion transport into organelles (Li et al., 2001; Kim et al., 2006). However, more detailed analyses, such as subcellular localization of the transporter, characterization of iron distribution, or the restoration of the phenotype by the addition of external iron, would be required to conclude this with certainty

Once metals cross the PBM, they are incorporated and used by the bacteroid. However, in spite of the huge number of genomic sequences available from rhizobia, very little is known about which transporters are involved in metal uptake and usage (Figure 1B). One of the first studies indicates that a $\mathrm{P}_{1 b}$-type $\mathrm{Cu}^{+}$-ATPase, FixI, is essential for nitrogen fixation (Kahn etal., 1989). FixI is responsible for transporting $\mathrm{Cu}^{+}$to the bacteroid periplasm. Within this compartment $\mathrm{Cu}^{+}$ 
is integrated into membrane-bound cytochrome cbb3 oxidase (Preisig etal., 1996), which is responsible for energy transduction in microaerobic environments. The $\mathrm{Ni}^{2+}$ importers HupE1 and HupE2 play a similar role in providing metal for the assembly of the $\mathrm{Ni}-\mathrm{Fe}$ cofactor of hydrogenase (Brito et al., 2010). No direct evidence for an iron importer is available, but there is evidence of protective mechanisms against the local accumulation of toxic concentrations of this element. For example, the $\mathrm{P}_{1 b}$-type ATPase, $\mathrm{Nia}$, is responsible for detoxifying excess $\mathrm{Fe}^{2+}$ that accumulates upon the massive entry of iron utilized to synthesize nitrogenase and other ferroproteins (Zielazinski et al., 2013).

The role of citrate in iron transport is important, although its role in SNF has not been completely elucidated. The citrate transporter FRD3, a multidrug and toxic compound extrusion (MATE) protein family member, has been shown in A. thaliana to be essential for iron transport across symplastically disconnected tissues (Roschzttardtz et al., 2011). Differences in the expression of citrate transporter GmFRD3 is a major contributing factor that distinguishes iron efficient soybean cultivars from iron inefficient cultivars. This finding suggests that iron efficient varieties exhibit increased tolerance to low iron due to increased solubility of ferric iron, which is facilitated by increased xylem citrate (Rogers et al., 2009). However, the function of GmFRD3 has not been examined in nodulating roots, therefore the role of this putative transporter within the context of SNF is still unknown. At the PBM a citrate transporter is also likely be important, since it has been shown that some rhizobia have a preference for citrate as their siderophore (LeVier et al., 1996). Takanashi et al. (2013) recently reported nodule-specific expression of a L. japonicus MATE family member, LjMATE1 (Figure 1B). LjMATE1 appears to have a substantial effect on iron distribution and nitrogenase activity in this organ (Takanashi et al., 2013). However, no precise localization of this transporter has been provided to date, and as a result the role of this transporter (long distance iron transport versus PBM translocation) could not be discerned.

\section{NODULE SENESCENCE AND SEED SET}

Nodule senescence is a programmed process coupled with the entry into the reproductive stage of the host plant life cycle (Van de Velde et al., 2006). Given that iron is a growth-limiting nutrient (Grotz etal., 1998), it has to be recycled from the senescent nodule. A number of studies indicate that this is the case (Burton et al., 1998; Rodríguez-Haas et al., 2013; Figure 1C). In young plants, some of this recycled iron might be redirected to younger parts of the nodule, but it would be predominantly transported to the shoot through the vasculature as the plant enters its reproductive stage. Burton et al. (1998) estimated that around $50 \%$ of the total nodular iron is recycled in the seed, in a process that is likely to be reminiscent of leaf senescence (Shi et al., 2012). Although no senescenceupregulated metal transporter has been identified, a senescent nodule-specific nicotianamine (NA) synthase has been cloned (Hakoyama etal., 2009). The synthesis of NA, the molecule responsible for intracellular and phloem metal transport (Curie et al., 2009), indicates that the released metals are transported within the phloem using an unknown Yellow Stripe-like (YSL) transporter, since YSLs are responsible for NA-metal transport (Curie et al., 2009).

The steps leading to cell death during senescence include degradation of plant tissue via free radical oxidation (Thompson et al., 1987). Free radical production in planta can be catalyzed by transition metals in the Fenton reaction (Stohs and Bagchi, 1995). Given the high concentration of iron in the nodule, it is likely that it is responsible for accelerating free radical production and eventual senescence (Bhattacharjee, 2005), as evidenced by the strong reduction in nodular deoxyribose degradation and linolenic acid peroxidation in the presence of the iron chelator, desferrioxamine (Becana and Klucas, 1992). No evidence exists for the involvement of other metals in this process, especially given the fact that concentrations of other catalytic metals are likely too low to contribute.

\section{FUTURE DIRECTIONS}

Although we have learned a great deal about the developmental and signaling processes involved in SNF in recent years, many questions remain about the molecular mechanisms by which nutrients, metals in particular, are transported to and from developing and mature nodules. Recent advances in high-resolution elemental analysis have been used to show changes in iron localization in indeterminate nodules (Rodríguez-Haas et al., 2013). Continued use of these and other elemental localization techniques (for review, see Samira et al., 2013; Zhao et al., 2014) such as energy-dispersive X-ray analysis or nanoSIMS to detect other elements should facilitate great strides in understanding metal distribution and translocation in SNF in the near future.

Recent transcriptomic approaches have also been particularly useful for identifying whole-genome responses involved in nutrient translocation and assimilation during various developmental stages of SNF. Transcriptional profiles at the onset of Mesorhizobium loti infection, during nodule primordia initiation and nodule organogenesis, and at the onset of nitrogen fixation indicate that there is little overlap between transcripts present at the earlier stages of infection and those present in fully developed nodules (Takanashi et al., 2012). This same study led to the discovery of LjMATE1, the putative dicarboxylic acid (citrate) transporter described above. Additionally, transcripts involved in the transport of carbohydrates, metals, and peptides are abundant at all stages of nodule development. Transcriptomic analysis of L. japonicus nodules of primary and lateral roots, followed by non-biased metabolic profiling, revealed that the majority of nodule-specific genes are involved in carbon and amino acid metabolism, while 5\% are involved in transport of metabolites or inorganic ions (Colebatch et al., 2004). Molecular genetic analysis of candidate genes identified by these studies should greatly enhance our understanding of regulatory processes that facilitate nutrient transport for SNF.

Overall, few studies have examined genotypic difference in response to metal availability in the context of SNF. So the question remains: what part of the changes in the nodule metallotranscriptome are metal dependent and which are symbiosisdependent? Time course and split root experiments of nodulating and non-nodulating roots under nutrient-sufficient and-deficient conditions followed by cell-specific transcriptional, proteomic, 
and metabolic profiling could begin to answer the question above. Furthermore, the application of modeling approaches and comparative studies will allow for the identification of metal homeostasis factors that are specific to symbiotic interactions and enable efforts for increased production of leguminous crops.

\section{ACKNOWLEDGMENTS}

We thank Drs. Rosangela Sozzani, Jeff Gillikin, and Devarshi Selote for review of the manuscript. Funding was provided by U.S. National Science Foundation (grants no. MCB1120937, MCB1247427), the U.S. Department of Agriculture (grant no. NC02380) and the North Carolina Agricultural Research Service (to Terri A. Long), the Ramón y Cajal Fellowship (RYC2010-06363), the Marie Curie International Reintegration Grant (IRG-2010-276771), and the Spanish Ministry of Economy and Competitiveness (AGL.2012-32974; to Manuel GonzálezGuerrero).

\section{REFERENCES}

Andaluz, S., Rodríguez-Celma, J., Abadía, A., Abadía, J., and López-Millán, A.-F. (2009). Time course induction of several key enzymes in Medicago truncatula roots in response to Fe deficiency. Plant Physiol. Biochem. 47, 1082-1088. doi: 10.1016/j.plaphy.2009.07.009

Andriankaja, A., Boisson-Dernier, A., Frances, L., Sauviac, L., Jauneau, A., Barker, D. G., et al. (2007). AP2-ERF transcription factors mediate Nod factor dependent Mt ENOD11 activation in root hairs via a novel cis-regulatory motif. Plant Cell 19, 2866-2885. doi: 10.1105/tpc.107.052944

Bashir, K., Takahashi, R., Nakanishi, H., and Nishizawa, N. K. (2013). The road to micronutrient biofortification of rice: progress and prospects. Front Plant Sci. 4:15. doi: 10.3389/fpls.2013.00015

Becana, M., and Klucas, R. V. (1992). Transition metals in legume root nodules: irondependent free radical production increases during nodule senescence. Proc. Natl. Acad. Sci. U.S.A. 89, 8958-8962. doi: 10.1073/pnas.89.19.8958

Bhattacharjee, S. (2005). Reactive oxygen species and oxidative burst: roles in stress, senescence and signal transduction in plants. Curr. Sci. 89, 1113-1121.

Brito, B., Martínez, M., Fernández, D., Rey, L., Cabrera, E., Palacios, J. M., et al. (1997). Hydrogenase genes from Rhizobium leguminosarum bv. viciae are controlled by the nitrogen fixation regulatory protein nifA. Proc. Natl. Acad. Sci U.S.A. 94, 6019-6024. doi: 10.1073/pnas.94.12.6019

Brito, B., Palacios, J., Hidalgo, E., Imperial, J., and Ruiz-Argüeso, T. (1994). Nickel availability to pea (Pisum sativum L.) plants limits hydrogenase activity of $i$ bv. viciae bacteroids by affecting the processing of the hydrogenase structural subunits. J. Bacteriol. 176, 5297.

Brito, B., Prieto, R. I., Cabrera, E., Mandrand-Berthelot, M. A., Imperial, J., RuizArgueso, T., et al. (2010). Rhizobium leguminosarum hupE encodes a nickel transporter required for hydrogenase activity. J. Bacteriol. 192, 925-935. doi: 10.1128/JB.01045-09

Burton, J. W., Harlow, C., and Theil, E. C. (1998). Evidence for reutilization of nodule iron in soybean seed development. J. Plant Nutr. 21, 913-927. doi: 10.1080/01904169809365453

Charpentier, M., Bredemeier, R., Wanner, G., Takeda, N., Schleiff, E., and Parniske, M. (2008). Lotus japonicus CASTOR and POLLUX are ion channels essential for perinuclear calcium spiking in legume root endosymbiosis. Plant Cell 20, 3467-3479. doi: 10.1105/tpc.108.063255

Charpentier, M., Vaz Martins, T., Granqvist, E., Oldroyd, G. E., and Morris, R. J. (2013). The role of DMI1 in establishing Ca $(2+)$ oscillations in legume symbioses. Plant Signal. Behav. 8, e22894. doi: 10.4161/psb.22894

Colebatch, G., Desbrosses, G., Ott, T., Krusell, L., Montanari, O., Kloska, S., et al. (2004). Global changes in transcription orchestrate metabolic differentiation during symbiotic nitrogen fixation in Lotus japonicus. Plant J. 39, 487-512. doi: 10.1111/j.1365-313X.2004.02150.x

Curie, C., Alonso, J. M., Le Jean, M., Ecker, J. R., and Briat, J. F. (2000). Involvement of NRAMP1 from Arabidopsis thaliana in iron transport. Biochem. J. 347, 749-755. doi: 10.1042/0264-6021:3470749
Curie, C., Cassin, G., Couch, D., Divol, F., Higuchi, K., Le Jean, M., et al. (2009). Metal movement within the plant: contribution of nicotianamine and yellow stripe 1-like transporters. Ann. Bot. 103, 1-11. doi: 10.1093/aob/ $\operatorname{mcn} 207$

Emerich, D. W., Ruiz-Argüeso, T., Ching, T. M., and Evans, H. J. (1979). Hydrogendependent nitrogenase activity and ATP formation in Rhizobium japonicum bacteroids. J. Bacteriol. 137, 153-160.

Frausto da Silva, J. J. R., and Williams, R. J. P. (eds). (1991). The Biological Chemistry of the Elements, the Inorganic Chemistry of Life. Oxford: Clarendon Press. doi: 10.1016/0307-4412(92)90039-O

Grotz, N., Fox, T., Connolly, E., Park, W., Guerinot, M. L., and Eide, D. (1998). Identification of a family of zinc transporter genes from Arabidopsis that respond to zinc deficiency. Proc. Natl. Acad. Sci. U.S.A. 95, 7220-7224. doi: $10.1073 /$ pnas.95.12.7220

Hakoyama, T., Niimi, K., Yamamoto, T., Isobe, S., Sato, S., Nakamura, Y., et al. (2012). The integral membrane protein SEN1 is required for symbiotic nitrogen fixation in Lotus japonicus nodules. Plant Cell Physiol. 53, 225-236. doi: $10.1093 / \mathrm{pcp} / \mathrm{pcr} 167$

Hakoyama, T., Watanabe, H., Tomita, J., Yamamoto, A., Sato, S., Mori, Y., et al. (2009). Nicotianamine synthase specifically expressed in root nodules of Lotus japonicus. Planta 230, 309-317. doi: 10.1007/s00425-009-0944-0

Hallsworth, E. G., Wilson, S. B., and Greenwood, E. A. (1960). Copper and cobalt in nitrogen fixation. Nature 187, 79-80. doi: 10.1038/187079a0

Jamet, A., Sigaud, S., Van De Sype, G., Puppo, A., and Herouart, D. (2003). Expression of the bacterial catalase genes during Sinorhizobium meliloti-Medicago sativa symbiosis and their crucial role during the infection process. Mol. Plant Microbe Interact. 16, 217-225. doi: 10.1094/MPMI.2003.16.3.217

Jin, C. W., He, Y. F., Tang, C. X., Wu, P., and Zheng, S. J. (2006). Mechanisms of microbially enhanced Fe acquisition in red clover (Trifolium pratense L.). Plant Cell Environ. 29, 888-897. doi: 10.1111/j.1365-3040.2005.01468.x

Kahn, D., David, M., Domergue, O., Daveran, M. L., Ghai, J., Hirsch, P. R., etal. (1989). Rhizobium meliloti fixGHI sequence predicts involvement of a specific cation pump in symbiotic nitrogen fixation. J. Bacteriol. 171, 929-939.

Kaiser, B. N., Moreau, S., Castelli, J., Thomson, R., Lambert, A., Bogliolo, S., et al. (2003). The soybean NRAMP homologue, GmDMT1, is a symbiotic divalent metal transporter capable of ferrous iron transport. Plant J. 35, 295-304. doi: 10.1046/j.1365-313X.2003.01802.x

Kalo, P., Gleason, C., Edwards, A., Marsh, J., Mitra, R. M., Hirsch, S., et al. (2005). Nodulation signaling in legumes requires NSP2, a member of the GRAS family of transcriptional regulators. Science 308, 1786-1789. doi: 10.1126/science.1110951

Kijne, J. W., Smit, G., Diaz, C. L., and Lugtenberg, B. J. (1988). Lectin-enhanced accumulation of manganese-limited Rhizobium leguminosarum cells on pea root hair tips. J. Bacteriol. 170, 2994-3000.

Kim, S. A., Punshon, T., Lanzirotti, A., Li, L., Alonso, J. M., Ecker, J. R., et al. (2006). Localization of iron in Arabidopsis seed requires the vacuolar membrane transporter VIT1. Science 314, 1295-1298. doi: 10.1126/science.1132563

Klucas, R. V., Hanus, F. J., Russell, S. A., and Evans, H. J. (1983). Nickel: a micronutrient element for hydrogen-dependent growth of Rhizobium japonicum and for expression of urease activity in soybean leaves. Proc. Natl. Acad. Sci. U.S.A. 80, 2253. doi: $10.1073 /$ pnas.80.8.2253

Klug, A. (2010). The discovery of zinc fingers and their applications in gene regulation and genome manipulation. Annu. Rev. Biochem. 79, 213-231. doi: 10.1146/annurev-biochem-010909-095056

Leborgne-Castel, N., Adam, T., and Bouhidel, K. (2010). Endocytosis in plantmicrobe interactions. Protoplasma 247, 177-193. doi: 10.1007/s00709-010-01958

LeVier, K., Day, D. A., and Guerinot, M. L. (1996). Iron uptake by symbisomes from soybean root nodules. Plant Physiol. 111, 893-900. doi: 10.1104/pp.111.3.893

Li, L., Chen, O. S., McVey Ward, D., and Kaplan, J. (2001). CCC1 is a transporter that mediates vacuolar iron storage in yeast. J. Biol. Chem. 276, 29515-29519. doi: 10.1074/jbc.M103944200

Lin, W., Chai, J., Love, J., and Fu, D. (2010). Selective electrodiffusion of zinc ions in a Zrt-, Irt-like protein, ZIPB. J. Biol. Chem. 285, 39013-39020. doi: 10.1074/jbc.M110.180620

Moreau, S., Thomson, R. M., Kaiser, B. N., Trevaskis, B., Guerinot, M. L., Udvardi, M. K., et al. (2002). GmZIP1 encodes a symbiosis-specific zinc transporter in soybean. J. Biol. Chem. 277, 4738-4746. doi: 10.1074/jbc.M106754200 
Morrissey, J., and Guerinot, M. L. (2009). Iron uptake and transport in plants: the good, the bad, and the ionome. Chem. Rev. 109, 4553-4567. doi: $10.1021 / \mathrm{cr} 900112 \mathrm{r}$

Nevo, Y., and Nelson, N. (2006). The NRAMP family of metal-ion transporters. Biochim. Biophys. Acta 1763, 609-620. doi: 10.1016/j.bbamcr.2006.05.007

Oldroyd, G. E. D., and Downie, J. A. (2004). Calcium, kinases and nodulation signalling in legumes. Nat. Rev. Mol. Cell Biol. 5, 566-576. doi: 10.1038/nrm1424

Peiter, E., Sun, J., Heckmann, A. B., Venkateshwaran, M., Riely, B. K., Otegui, M. S., et al. (2007). The Medicago truncatula DMI1 protein modulates cytosolic calcium signaling. Plant Physiol. 145, 192-203. doi: 10.1104/pp.107.097261

Preisig, O., Zufferey, R., Thony-Meyer, L., Appleby, C. A., and Hennecke, H. (1996). A high-affinity cbb3-type cytochrome oxidase terminates the symbiosis-specific respiratory chain of Bradyrhizobium japonicum. J. Bacteriol. 178, 1532-1538.

Reedy, C. J., and Gibney, B. R. (2004). Heme protein assemblies. Chem. Rev. 104, 617-649. doi: 10.1021/cr0206115

Rellán-Álvarez, R., Giner-Martínez-Sierra, J., Orduna, J., Orera, I., RodríguezCastrillón, J. A., García-Alonso, J. I., et al. (2010). Identification of a tri-iron(III), tri-citrate complex in the xylem sap of iron-deficient tomato resupplied with iron: new insights into plant iron long-distance transport. Plant Cell Physiol. 51, 91-102. doi: 10.1093/pcp/pcp170

Rodríguez-Celma, J., Lin, W. D., Fu, G. M., Abadía, J., López-Millán, A.-F., and Schmidt, W. (2013). Mutually exclusive alterations in secondary metabolism are critical for the uptake of insoluble iron compounds by Arabidopsis and Medicago truncatula. Plant Physiol. 162, 1473-1485. doi: 10.1104/pp.113.220426

Rodríguez-Haas, B., Finney, L. A., Vogt, S., González-Melendi, P., Imperial, J. and González-Guerrero, M. (2013). Iron distribution through the developmental stages of Medicago truncatula nodules. Metallomics 5, 1247-1253. doi: $10.1039 / \mathrm{c} 3 \mathrm{mt} 00060 \mathrm{e}$

Rogers, E. E., Wu, X., Stacey, G., and Nguyen, H. T. (2009). Two MATE proteins play a role in iron efficiency in soybean. J. Plant Physiol. 166, 1453-1459. doi: 10.1016/j.jplph.2009.02.009

Roschzttardtz, H., Séguéla-Arnaud, M., Briat, J. F., Vert, G., and Curie, C. (2011). The FRD3 citrate effluxer promotes iron nutrition between symplastically disconnected tissues throughout Arabidopsis development. Plant Cell 23, 2725-2737. doi: 10.1105/tpc.111.088088

Rubio, M. C., Becana, M., Sato, S., James, E. K., Tabata, S., and Spaink, H. P. (2007). Characterization of genomic clones and expression analysis of the three types of superoxide dismutases during nodule development in Lotus japonicus. Mol. Plant Microbe Interact. 20, 262-275. doi: 10.1094/MPMI-20-3-0262

Samira, R., Stallmann, A., Massenburg, L. N., and Long, T. A. (2013). Ironing out the issues: integrated approaches to understanding iron homeostasis in plants. Plant Sci. 210, 250-259. doi: 10.1016/j.plantsci.2013.06.004

Seliga, H. (1990). The effect of copper nutrition on symbiotic nitrogen fixation in yellow lupine (Lupinus luteus L.) plants. Acta Physiol. Plant. 12, 287-291.

Seliga, H. (1993). The role of copper in nitrogen fixation in Lupinus luteus L. Plant Soil 155-156, 349-352. doi: 10.1007/BF00025054

Shi, R., Weber, G., Koster, J., Reza-Hajiresaei, M., Zou, C., Zhang, F., et al. (2012). Senescence-induced iron mobilization in source leaves of barley (Hordeum vulgare) plants. New Phytol. 195, 372-383. doi: 10.1111/j.1469-8137.2012.04165.x

Singh, S., and Parniske, M. (2012). Activation of calcium- and calmodulindependent protein kinase (CCaMK), the central regulator of plant root endosymbiosis. Curr. Opin. Plant Biol. 15, 444-453. doi: 10.1016/j.pbi.2012.04.002

Slatni, T., Vigani, G., Salah, I. B., Kouas, S., Dell'Orto, M., Gouia, H., et al. (2011). Metabolic changes of iron uptake in N2-fixing common bean nodules during iron deficiency. Plant Sci. 181, 151-158. doi: 10.1016/j.plantsci.2011.04.015

Slatni, T., Dell'Orto, M., Ben Salah, I., Vigani, G., Smaoui, A., Gouia, H., et al. (2012). Immunolocalization of $\mathrm{H}^{+}$-ATPase and IRT1 enzymes in $\mathrm{N}_{2}$-fixing common bean nodules subjected to iron deficiency. J. Plant Physiol. 169, 242-248. doi: 10.1016/j.jplph.2011.10.003

Snowball, K., Robson, A. D., and Loneragan, J. F. (1980). The effect of copper on nitrogen fixation in subterranean clover (Trifolium subterraneum). New Phytol. 85, 63-72. doi: 10.1111/j.1469-8137.1980.tb04448.x
Stohs, S. J., and Bagchi, D. (1995). Oxidative mechanisms in the toxicity of metal ions. Free Radic. Biol. Med. 18, 321-336. doi: 10.1016/0891-5849(94)00159-H

Stults, L. W., O’Hara, E. B., and Maier, R. J. (1984). Nickel is a component of hydrogenase in Rhizobium japonicum. J. Bacteriol. 159, 153-158.

Taga, M. E., and Walker, G. C. (2010). Sinorhizobium meliloti requires a cobalamindependent ribonucleotide reductase for symbiosis with its plant host. Mol. Plant Microbe interact. 23, 1643-1654. doi: 10.1094/MPMI-07-10-0151

Takanashi, K., Takahashi, H., Sakurai, N., Sugiyama, A., Suzuki, H., Shibata, D., et al. (2012). Tissue-specific transcriptome analysis in nodules of Lotus japonicus. Mol. Plant Microbe Interact. 25, 869-876. doi: 10.1094/MPMI-01-120011-R

Takanashi, K., Yokosho, K., Saeki, K., Sugiyama, A., Sato, S., Tabata, S., et al. (2013). LjMATE1: a citrate transporter responsible for iron supply to the nodule infection zone of Lotus japonicus. Plant Cell Physiol. 54, 585-594. doi: 10.1093/pcp/pct019

Terry, R. E., Soerensen, K. U., Jolley, V. D., and Brown, J. C. (1991). The role of active Bradyrhizobium japonicum in iron stress response of soy-beans. Plant Soil 130, 225-230. doi: 10.1007/BF00011877

Thompson, J. E., Legge, R. L., and Barber, R. F. (1987). The role of free radicals in senescence and wounding. New Phytol. 105, 317-344. doi: 10.1111/j.14698137.1987.tb00871.x

Udvardi, M., and Poole, P. S. (2013). Transport and metabolism in legume-rhizobia symbioses. Annu. Rev. Plant Biol. 64, 781-805. doi: 10.1146/annurev-arplant050312-120235

Van de Velde, W., Guerra, J. C. P. R., Keyser, A. D., De Rycke, R., Rombauts, S. P., Maunoury, N., et al. (2006). Aging in legume symbiosis. A molecular view on nodule senescence in Medicago truncatula. Plant Physiol. 141, 711-720. doi: 10.1104/pp.106.078691

van der Elst, F. H., McNaught, K. J., and Rolt, W. F. (1961). Effect of copper deficiency in white clover on nitrogen fixation. Nature 192, 1315-1315. doi: $10.1038 / 1921315 \mathrm{a} 0$

Vasse, J., De Billy, F., Camut, S., and Truchet, G. (1990). Correlation between ultrastructural differentiation of bacteroids and nitrogen fixation in alfalfa nodules. J. Bacteriol. 172, 4295-4306.

Waldron, K. J., and Robinson, N. J. (2009). How do bacterial cells ensure that metalloproteins get the correct metal? Nat. Rev. Microbiol. 7, 25-35. doi: 10.1038/nrmicro2057

Zhao, F. J., Moore, K. L., Lombi, E., and Zhu, Y. G. (2014). Imaging element distribution and speciation in plant cells. Trends Plant Sci. doi: 10.1016/j.tplants.2013.12.001 [Epub ahead of print].

Zielazinski, E. L., González-Guerrero, M., Subramanian, P., Stemmler, T. L., Argüello, J. M., and Rosenzweig, A. C. (2013). Sinorhizobium meliloti $\mathrm{Nia}$ is a P-ATPase expressed in the nodule during plant symbiosis and is involved in Ni and Fe transport. Metallomics 5, 1614-1623. doi: 10.1039/c3mt $00195 d$

Conflict of Interest Statement: The authors declare that the research was conducted in the absence of any commercial or financial relationships that could be construed as a potential conflict of interest.

Received: 30 November 2013; paper pending published: 06 January 2014; accepted: 29 January 2014; published online: 13 February 2014.

Citation: González-Guerrero M, Matthiadis A, Sáez Á and Long TA (2014) Fixating on metals: new insights into the role of metals in nodulation and symbiotic nitrogen fixation. Front. Plant Sci. 5:45. doi: 10.3389/fpls.2014.00045

This article was submitted to Plant Nutrition, a section of the journal Frontiers in Plant Science.

Copyright (C) 2014 González-Guerrero, Matthiadis, Sáez and Long. This is an openaccess article distributed under the terms of the Creative Commons Attribution License (CC BY). The use, distribution or reproduction in other forums is permitted, provided the original author(s) or licensor are credited and that the original publication in this journal is cited, in accordance with accepted academic practice. No use, distribution or reproduction is permitted which does not comply with these terms. 